A C T A C H E M I C A S C A N D I N A V I C A 19 (1965) 1271-1285

\title{
New Heteroaromatic Systems Derived from o-Formylthiopheneboronic Acids
}

\author{
SALO GRONOWITZ* and ANDREAS BUGGE* \\ Chemical Institute, University of Oslo, Blindern, Oslo 3, Norway
}

\begin{abstract}
Formylthiopheneboronic acids were prepared through halogenmetal interconversion between the ethylene acetals of bromothiophene aldehydes and butyllithium at $-70^{\circ}$ followed by the reaction of the thienyllithium derivatives with butyl borate and consequent hydrolysis. The reaction of 2-formyl-3-thiopheneboronic acid with phenylhydrazine and hydroxylamine led to heteroaromatic boron compounds, namely 4-hydroxy-5-phenyl-4,5-borazarothieno[2,3-c]pyridine $(\mathrm{XV})$ and 4-hydroxy-4,5-boroxarothieno[2,3-c]pyridine (XXI). On the other hand the reaction of 4-formyl-3-thiopheneboronic acid with the same reagents led to the phenyl hydrazone and the oxime, respectively, in accordance with the expectations that an aromatic ring is not obtained when annelating at the 3,4-positions in thiophene. Both 2-formyl-3-thiopheneboronic acid and 4-formyl3-thiopheneboronic acid gave cyclic boron derivatives with hydrazine, namely 4-hydroxy-4,5-borazarothieno[2,3-c]pyridine (XVIII) and 7-hydroxy-7,6-borazarothieno[3,4-c]pyridine (XIX). It is, however, highly probable that aromatization is not the driving force for the cyclisation in the latter case. While XVIII is stable towards acid hydrolysis, a property characteristic of heteroaromatic boron compounds, XIX is easily hydrolysed by dilute acid. Structure determination of the boron derivatives obtained was carried out by NMRand mass-spectroscopy.
\end{abstract}

During the last eight years interesting work on the existence and properties of new heteroaromatic compounds has been published by Dewar and coworkers ${ }^{1}$ (for review cf. Ref. 2). In these compounds a pair of adjacent carbon atoms in a classical aromatic system are replaced by a boron and a nitrogen atom or by a boron and an oxygen atom. In a recent paper Dewar and Dougherty showed that the compounds obtained on reaction of $o$-formylphenylboronic acid with hydrazine or hydroxylamine were cyclic and could be considered to be derived from isoquinoline by replacement of the 4- and 3-carbons of this ring system with boron and nitrogen or boron and oxygen, respectively. ${ }^{3}$ With hydrazine Dewar and Dougherty thus obtained bis-(4,3-

* Present address: Institute of Chemistry, University of Lund, Lund, Sweden.

'Acta Chem. Scand. 19 (1965) No. 6 
borazaro-4-isoquinolyl)ether (I); also phenylhydrazine gave the corresponding ether, while methylhydrazine yielded the corresponding hydroxyl derivative (II). Hydroxylamine yielded 4-hydroxy-4,3-boroxaroisoquinoline (III).

Conclusions regarding the aromatic nature of these compounds are based on the stability of the carbon-boron and boron-nitrogen bonds towards hydrolysis, making for instance aromatic substitution possible, ${ }^{4-7}$ and on the similarity of their UV-spectra with those of the corresponding classical aromatic systems. ${ }^{3,8-9}$

The stability of boronophtalide (IV) towards hydrolysis ${ }^{10}$ makes some of the chemical evidence for aromaticity less convincing and might indicate that the cyclic nature of these heterocyclic boron compounds in itself is responsible for their stability. Dewar and Dietz showed, ${ }^{11}$ however, that the behaviour of 2-hydroxy-2,1-borazaronaphthalene (V) towards bases differed from those of acyclic boronic acids. The reason for this was considered to be the following. While acyclic boronic acids exhibit their acidic properties by coordinating a hydroxyl ion, ${ }^{12,13}$ such coordination would, however, remove the boron atom from conjugation and the aromatic stabilization energy would be lost. The heterocyclic boron compound therefore exhibits its acidic properties by losing a proton. Also the influence of substituents on the nitrogen<smiles>C1=NN=[Se](Oc2nccc3ccccc23)c2ccccc21</smiles>

I<smiles>OB1OCc2ccccc21</smiles>

IV<smiles></smiles>

II<smiles>O[Se]1=CC=c2ccccc2=N1</smiles>

v<smiles>OB1ON=Cc2ccccc21</smiles>

III<smiles>C[Se]1Nc2ccccc2-c2ccccc21</smiles>

or boron atom on the stability of 9,10-borazarophenanthrenes is in accordance with aromaticity. ${ }^{14},{ }^{15}$ More difficult to understand is the low dipole moment observed for 10-methyl-10,9-borazarophenanthrene (VI) suggesting that the contribution of the dipolar resonance structure, characteristic of aromaticity, is small. ${ }^{14}$ (However, Dewar ${ }^{2}$ has an apparently satisfactory explanation for this too.).

In the thiophene series additional tests of the aromaticity of this type of compounds is possible. 4,5-Borazarothieno[2,3-c]pyridines * (VII) are analogues of thieno[2,3-c]pyridine (VIII) which is as stable an aromatic

\footnotetext{
* The nomenclature of the Ring Index and of Dewar and Dietz will be used.
} 


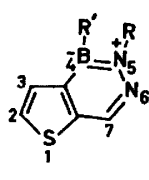

vII<smiles></smiles>

XI<smiles>c1cc2ccsc2cn1</smiles>

VIII<smiles>O=C(O)c1ccsc1</smiles>

XII<smiles>[R3][R3]1c2c(nn1[R])C1=ISC=C12</smiles>

IX<smiles>O=Cc1cscc1O</smiles>

XIII<smiles>c1ccc2cscc2c1</smiles>

$x$<smiles></smiles>

XIV

system as thionaphthene. On the other hand the 7,6-borazarothieno[3,4-c]pyridine system (IX) is an analogue to isothionaphthene (X). This compound has recently been prepared and is very unstable. ${ }^{16}$ It decomposes after a few days at $-30^{\circ}$ and easily undergoes the Diels-Alder reaction with maleic anhydride, which leads to the formation of the benzenoid ring system. Similar properties uncharacteristic of aromatic systems are shown by 2,5-dimethylthieno[3,4-c]thiophene (XI). ${ }^{17}$ One would therefore expect that the carbonyl derivatives of 2-formyl-3-thiopheneboronic acid (XII) would cyclise with elimination of water, while the derivatives of 4-formyl-3-thiopheneboronic acid (XIII) would not, if aromatic stabilization was the driving force for cyclisation. If cyclisation in itself led to stabilization there would be no reason to expect any large differences between annelation of a six-membered ring to the 2,3-position or to the 3,4-position of thiophene. Judging from the known dimensions of thiophene, ${ }^{18}$ one would even be led to suspect that ring-closure to the 2,3-position should be somewhat more difficult. For comparison we have also studied the hydrazones and oximes derived from 5-formyl-2thiopheneboronic acid (XIV) in which cases cyclisation is not possible.

\section{SYNTHESES AND PROPERTIES OF FORMYLTHIOPHENEBORONIC ACIDS}

The formylthiopheneboronic acids were easily obtained in yields between 50 and $60 \%$ through halogen-metal interconversion between the ethylene acetals of the corresponding bromothiophene aldehydes and butyllithium at $-70^{\circ},{ }^{19}$ followed by reaction of the thienyllithium derivatives with butyl borate and hydrolysis. 2-(3-bromo-2-thienyl)-1,3-dioxolane yielded in this way XII, 2-(4-bromo-3-thienyl)-1,3-dioxolane yielded XIII, and 2-(5-bromo2-thienyl)-1,3-dioxolane yielded XIV. The o-formylthiopheneboronic acids exist in the open aldehyde-acid form as they, like the 2,5-isomer, show a $\mathrm{C}=\mathrm{O}$ stretching frequency at $6.10 \mu$ and in their NMR-spectrum show absorption in the region $\left(\begin{array}{ll}0 & \tau\end{array}\right)$ characteristic of aldehydic hydrogens. Furthermore, these acids show the IR-absorption peaks characteristic of arylboronic acids. ${ }^{20,21}$ The stretching frequency of the $\mathrm{OH}$ occurs at $3.0 \mu$ and of the $\mathrm{B}=\mathrm{O}$ at $7.42 \mu$. All three acids also show absorption in the region $14.2-14.7 \mu^{20}, 13.6-14.5 \mu^{21}$ which is considered characteristic of boronic anhydrides. This could indicate

Acta Chem. Scand. 19 (1965) No. 6 
that the acids are partly anhydrated. However, many thiophene derivatives have absorption in this region and the elementary analyses indicate that the amount of anhydrides must be small.

As already pointed out by Serafinowa and Makosza, ${ }^{21}$ we could not confirm the statement of Santucci and Gilman ${ }^{22}$ that the B-O stretching bands occurred between 8.35-8.5 $\mu$, for although many of the formylthiopheneboronic acids or bromothiopheneboronic acids have one or two bands in this and adjacent regions, some have not. Similarly, several of the substituted thiopheneboronic acids show no absorption between 9.1-9.2 $\mu$ and 9.7-9.8 $\mu$ considered characteristic of the $\mathrm{C}-\mathrm{B}$ bond by Santucci and Gilman. ${ }^{22} \mathrm{As}$ pointed out by Serafinowa and Makosza, ${ }^{21}$ the bands observed in the benzeneboronic acids are probably due to the type of substitution in the benzene ring.

In the NMR-spectrum of XIV in dimethyl sulphoxide (DMSO) the aldehyde resonance $(-0.05 \tau)$ as expected is sharp as position 5 is blocked. The thiophenic hydrogen bands occur as two doublets at $1.95 \tau$ and $2.14 \tau$ with a coupling constant of $3.8 \mathrm{c} / \mathrm{s}$, characteristic of $J_{34}$ in thiophenes.

In XIII the long-range coupling between the aldehydic hydrogen in the 4-position and the 2 ring hydrogen $(0.9 \mathrm{c} / \mathrm{s})^{23}$ is observed both in acetone and in DMSO solution. In the former solvent, however, the $\mathrm{B}(\mathrm{OH})_{2}$ resonance coincides with the 2-hydrogen resonance which occurs at highest field $(1.75 \tau)$. The formyl group thus has a much larger deshielding effect on its ortho hydrogen as the resonance of hydrogen 5 appears at $1.21 \tau$. The observed coupling $(3.0 \mathrm{c} / \mathrm{s})$ falls in the region found for $J_{25}$ in 3,4-disubstituted thiophenes. ${ }^{23}$ Judging from the structure of the 2-formyl group resonance of XII the 2-formyl group shows small long-range couplings to both ring hydrogens, which both show broadened doublets at $1.89 \tau$ and $2.46 \tau$ in DMSO solution. The ringcoupling constant is $5.1 \mathrm{c} / \mathrm{s}$. In acetone solution the $\mathrm{B}(\mathrm{OH})_{2}$ resonance partly coincides with the low field thiophenic resonance, which, however, shows a resolved splitting $(0.9 \mathrm{c} / \mathrm{s})$ due to long-range coupling, which jdentifies this band as that of the 5-hydrogen. It is known that in 2-thiophene aldehydes the larger long-range coupling is to position 5.

As is normal for boronic acids, these compounds show no definite melting or decomposition points as they are easily dehydrated on heating to yield anhydrides.

\section{REACTIONS OF FORMYL BORONIC ACIDS WITH CARBONYL REAGENTS}

The reaction of XII with phenylhydrazine carried out under the same conditions used in the reaction of $o$-formyl benzeneboronic acid ${ }^{3}$ yielded a crystalline compound, which elementary analysis showed to have the composition $\mathrm{C}_{11} \mathrm{H}_{9} \mathrm{BN}_{2} \mathrm{OS}$. In its NMR-spectrum (Fig. 1) in DMSO solution it shows four bands with the relative intensities of 1:1:2:5 at $1.05 \tau, 1.57 \tau, 2.08 \tau$, and $2.5 \tau$, which indicates that the compound is 4-hydroxy-5-phenyl-4,5borazarothieno[2,3-c]pyridine (XV). Through comparison with the NMRspectra of the compounds described below, the $1.05 \tau$ band is assigned to the hydroxy hydrogen, the $1.57 \tau$ band to the 7-hydrogen, the $2.08 \tau$ band to the thiophenic hydrogens, the resonances of which coincide in this solvent, and the broad band around $2.5 \tau$ to the five phenyl hydrogens. The analysis and 
Fig. 1. NMR-spectrum at $60 \mathrm{Mc} / \mathrm{s}$ of 4-hydroxy-5-phenyl-4,5-borazarothieno-

[2,3-c]pyridine in DMSO solution.

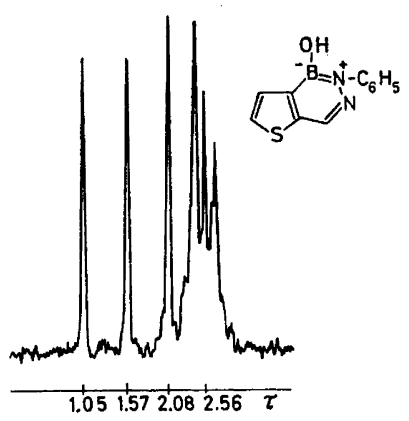

the NMR-spectrum could also be in accordance with the trimeric anhydride XVI a. In such case the band at $1.05 \tau$ assigned to the hydroxyl hydrogen would be due to the NH of XVI a. However, the mass spectrum of the product (Fig. 2) clearly proves the structure to be XVI, as it shows a strong peak at $m / e 228$ due to the molecular ion. The weaker peak at $m / e 438$ corresponding to $2 \mathrm{M}-\mathrm{H}_{2} \mathrm{O}$, is most probably due to the molecular ion from the ether formed during the introduction of the sample. As mentioned before, such ethers are easily formed, and in the benzene analogue the ether $(I)$ is the product actually isolated from the reaction between $o$-formyl benzeneboronic acid and phenylhydrazine. A more detailed elucidation of the fragmentation pattern of XIII and of the other heteroaromatic compounds described in this paper will be
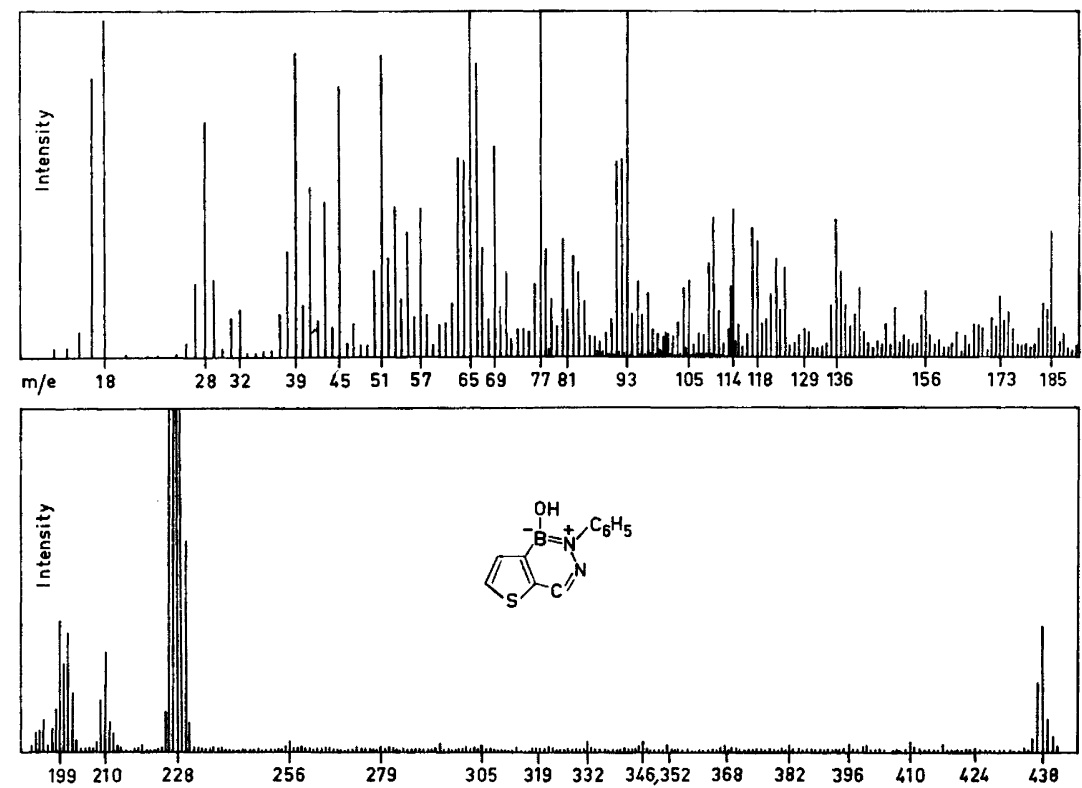

Fig. 2. Mass spectrum of 4-hydroxy-5-phenyl-4,5-borazarothieno[2,3-c]pyridine.

Acta Chem. Scand. 19 (1965) No. 6 
undertaken, when more experimental material is available. Ether-formation is also indicated by the behaviour of $\mathrm{XV}$ on heating. The compound first melts at $147-153^{\circ}$, crystallizes upon cooling and then melts at $188-190.5^{\circ}$, showing a different IR-spectrum.

The same reaction of XIII with phenylhydrazine on the other hand yielded a compound which analyzed as $\mathrm{C}_{11} \mathrm{H}_{11} \mathrm{BN}_{2} \mathrm{O}_{2} \mathrm{~S}$ and thus is simply the phenylhydrazone (XVI) of XIII. This is also quite clear from its NMR-spectrum in DMSO (Fig. 3), which shows a band at $-0.25 \tau$ ascribed to the NH hydrogen,

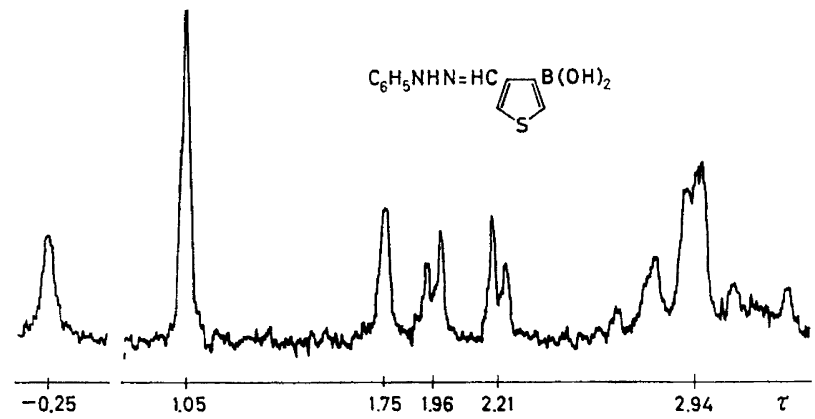

Fig. 3. NMR-spectrum at $60 \mathrm{Mc} / \mathrm{s}$ of 4-formyl-3-thiopheneboronic acid phenylhydrazone in DMSO solution.

a band with relative intensity 2 at $1.05 \tau$ ascribed to the hydroxyl groups of the boronic acid function and a peak at $1.75 \tau$ from the $\mathrm{C}-\mathrm{H}$ group of the side-chain. The two doublets at $1.96 \tau$ and $2.21 \tau$, with a coupling of $3.0 \mathrm{c} / \mathrm{s}$,

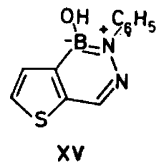<smiles></smiles><smiles>[R]B1[R9]OB([R6])O1</smiles>

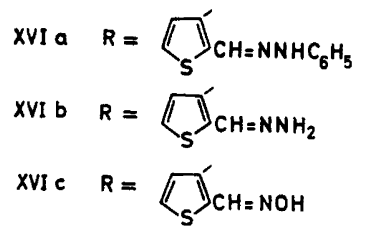

characteristic of 3,4-disubstituted thiophenes, arise from the thiophenic hydrogens, and finally the band with unresolved structure at $2.9 \tau$ containing five hydrogens belongs to the phenyl group.

The phenylhydrazone (XVII) of XIV for which cyclisation is not possible, shows a very similar NMR-spectrum (Fig. 4). The $\mathrm{N}-\mathrm{H}$ resonance occurs at $-0.24 \tau$. The $\mathrm{OH}$ resonance ${ }^{*}$ occurs at $1.81 \tau$ and the $\mathrm{CH}$ resonance at

* The position and form of the $\mathrm{B}(\mathrm{OH})_{2}$ resonance is very much dependent on the purity of the solvent and strong broadening of this band can often be observed. 


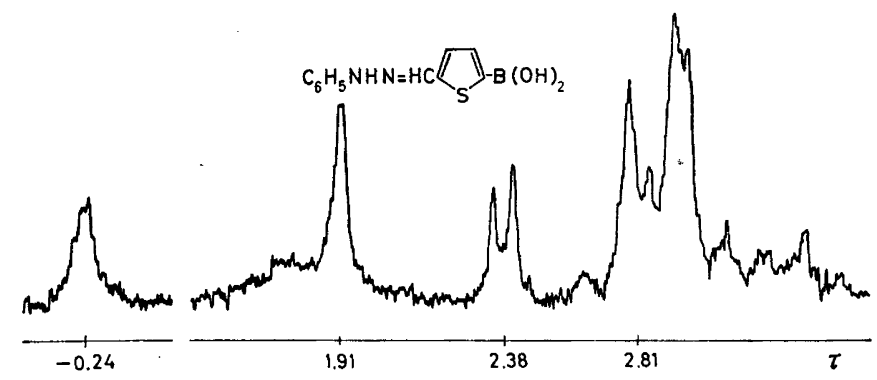

Fig. 4. NMR-spectrum at $60 \mathrm{Mc} / \mathrm{s}$ of 5-formyl-2-thiopheneboronic acid phenylhydrazone in DMSO solution.

$1.91 \tau$. One of the thiophenic hydrogen resonances occurs at $2.38 \tau$ as a doublet with a coupling of $3.4 \mathrm{c} / \mathrm{s}$, characteristic of 2,5-disubstituted thiophenes, while the other thiophene resonance falls into the phenyl hydrogen band and occurs at about 2.81 $\tau$. This phenylhydrazone easily undergoes deboronation. Attempts to recrystallize from acetic acid lead to 2-thiophene aldehyde phenylhydrazone.

The reaction between XII and hydrazine leads to the expected cyclic product, 4-hydroxy-4,5-borazarothieno[2,3-c]pyridine (XVIII). This is evident from elementary analysis and from its NMR-spectrum (Fig. 5) and mass
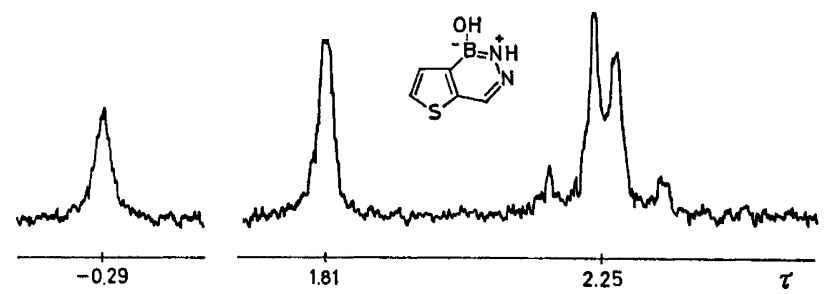

Fig. 5. NMR-spectrum at 60

$60 \mathrm{Mc} / \mathrm{s}$ of 4-hydroxy-4,5-borazarothieno[2,3-c]pyridine in DMSO solution.

spectrum. The $\mathrm{NH}$ resonance occurs at $-0.29 \tau$. The $\mathrm{OH}$ and $\mathrm{CH}$ resonances coincide at $1.81 \tau$ and the two thiophenic hydrogens occur as a strongly coupled AB-spectrum, at $2.21 \tau$ and $2.28 \tau$, with a coupling constant of $5.3 \mathrm{c} / \mathrm{s}$ characteristic for $J_{23}$ in thiophenes. ${ }^{23}$ The high field doublet shows additional splitting of about $0.5 \mathrm{c} / \mathrm{s}$ due to long-range coupling to the 7 -hydrogen.

The NMR-spectrum alone excludes the possibility that the product is the trimeric anhydride XVI b. For such a structure a band at around $5 \tau$, would be expected as we have observed in impure benzaldehyde hydrazone. The mass spectrum (Fig. 6) confirms the structure XVIII as it shows a strong peak at $m / e 152$ due to the molecular ion and again a weak peak due to the molecular ion from the ether at $2 \mathrm{M}-\mathrm{H}_{2} \mathrm{O}$ with m/e 286. Again ether-formation was indicated on heating XVIII. The compound melted first unsharply at

Acta Chem. Scand. 19 (1965) No. 6 


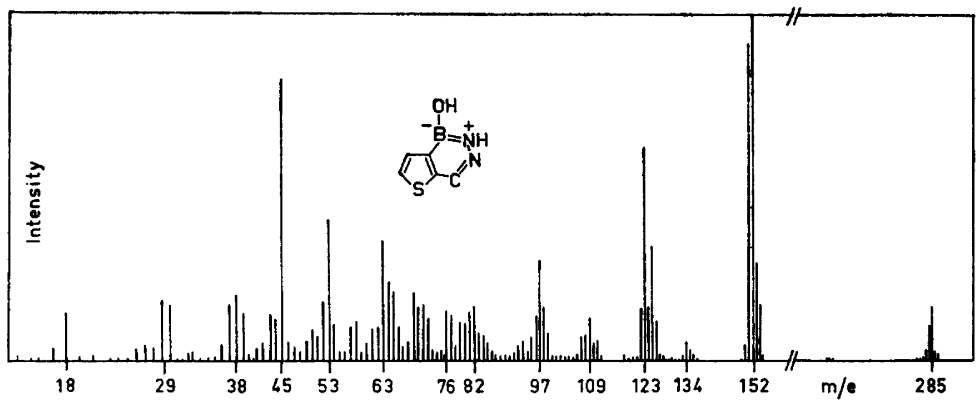

Fig. 6. Mass spectrum of 4-hydroxy-4,5-borazarothieno[2,3-c]pyridine.

$127-146^{\circ}$, but upon cooling and renewed melting point determination a sharp melting point at $160-161^{\circ}$ was observed, which most probably is the melting point of the ether.

However, perhaps somewhat unexpectedly, the product derived from the reaction of XIII with hydrazine is the cyclic 7-hydroxy-7,6-borazarothieno[3,4-c]pyridine (XIX). This is evident from the elementary analysis and from its NMR-spectrum (Fig. 7), which shows the NH resonance at $0.65 \tau$, the $\mathrm{OH}$ resonance at $1.61 \tau$. The quartet at $1.73 \tau$ with splittings of $0.7 \mathrm{c} / \mathrm{s}$ and $2.6 \mathrm{c} / \mathrm{s}$ is ascribed to the hydrogen in position 1 , the splittings being due to the crossring coupling to the hydrogen in position 4 and to the other hydrogen in position 3 (cf. below). The doublet at $2.00 \tau$ with a splitting of $2.6 \mathrm{c} / \mathrm{s}$ thus belongs to hydrogen 3 and the doublet at $2.09 \tau$ with a splitting of $0.7 \mathrm{c} / \mathrm{s}$ to hydrogen 4 of XIX.

Again the mass spectrum (Fig. 8) confirms the molecular weight assignment showing strong peaks at $m / e 152$ and 286 .

It is, however, possible that aromatization is not the driving force for ringclosure in this case. The reaction of aldehydes with hydrazine leads normally to azines and the hydrazones are in any case unstable compounds easily disproportionating to azines and free hydrazine. Thus for instance attempts to prepare the hydrazone of XIV in different ways failed, the product being the impure azine (XX).

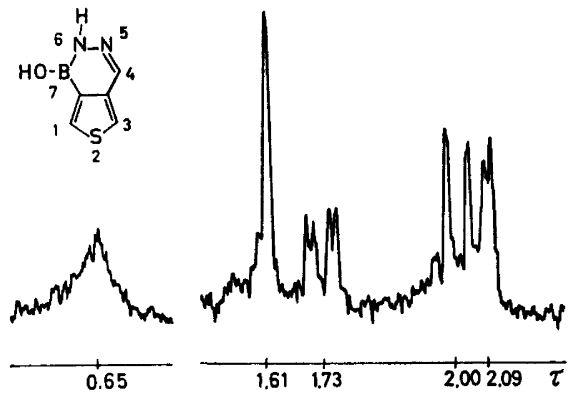

Fig. 7. NMR-spectrum at $60 \mathrm{Mc} / \mathrm{s}$ of 7-hydroxy-7,6-borazarothieno[3,4-c]pyridine in DMSO solution.

Acta Chem. Scand. 19 (1965) No. 6 


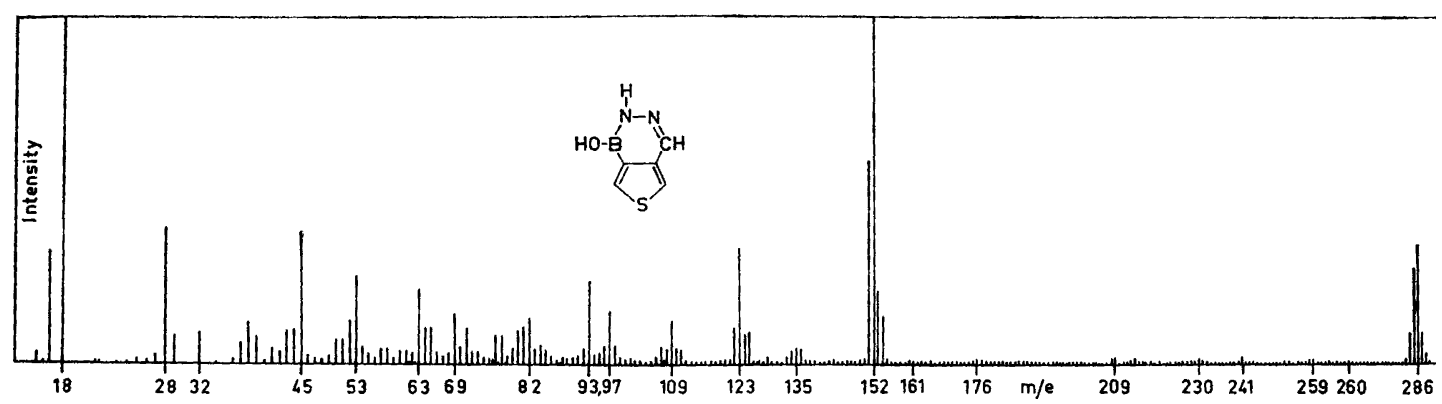

Fig. 8. Mass spectrum of 7-hydroxy-7,6-borazarothieno[3,4-c]pyridine.<smiles>Oc1ccc(Nc2ccccc2)s1</smiles>

XVII<smiles>O[R6]1n[nH]c2sccc12</smiles>

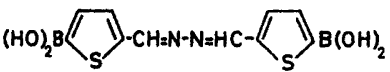

Preliminary chemical investigations are in accordance with this interpretation. XVIII was stable toward hydrolysis and was recovered almost quantitatively, when refluxed for $3 \mathrm{~h}$ with concentrated hydrochloric acid. Upon cooling, the hydrochloride of XVIII separated which upon treatment with water yielded XVIII. On the other hand heating of XIX with $2 \mathrm{~N}$ hydrochloric acid for only $10 \mathrm{~min}$ at $100^{\circ}$, yielded quite a different product, showing $\mathrm{C}=\mathrm{O}$ stretching frequency, which we have not yet identified. We are continuing our study of the chemical properties of these ring-systems.

In the reaction with hydroxylamine, however, XII led to the cyclic 4-hydroxy-4,5-boroxarothieno[2,3-c]pyridine (XXI), while XIII gave a normal oxime (XXII).

The structure of XXI follows again from elementary analyses, molecular weight determination by mass spectroscopy, and NMR-spectrum. The $\mathrm{OH}$ resonance occurs in DMSO solution at $0.46 \tau$, hydrogen 7 at $1.08 \tau$ and the two thiophene hydrogens at $1.95 \tau$ and $2.30 \tau$, with the characteristic $J_{45}$ coupling of thiophenes of $5.0 \mathrm{c} / \mathrm{s}$. In acetone solution (Fig. 9) a long-range coupling of $0.7 \mathrm{c} / \mathrm{s}$ between hydrogen 7 and the high-field thiophenic hydrogen resonance can easily be resolved in both bands. The absence of the characteristic low-field oximic $\mathrm{OH}$ at $-1 \tau$ alone excludes the trimeric boronic anhydride (XVI c), and the mass spectrum shows the molecular ion peak at $m / e$ 153. In this case no peak due to ether formation during injection is observed. The possibility that XXI could have the amine oxide structure XXI b, and III a corresponding structure has not been seriously considered,

Acta Chem. Scand. 19 (1965) No. 6 


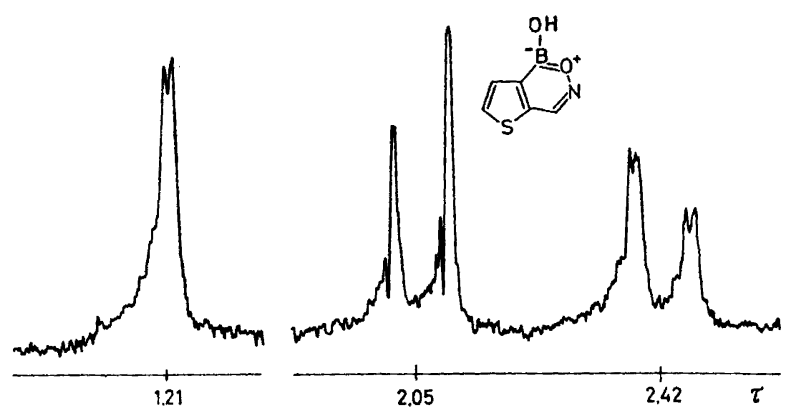

Fig. 9. NMR-spectrum at $60 \mathrm{Mc} / \mathrm{s}$ of 4-hydroxy-4,5-boroxarothieno[2,3-c]pyridine in acetone solution.

as aromatization in this case cannot be a driving force and one therefore would expect ring closure when treating XIII with hydroxylamine. The oxime XXII was very difficult to purify, probably due to facile deboronation, and satisfactory elementary analyses were not obtained. However, its NMRspectrum (Fig. 10) leaves no doubt regarding its open structure.

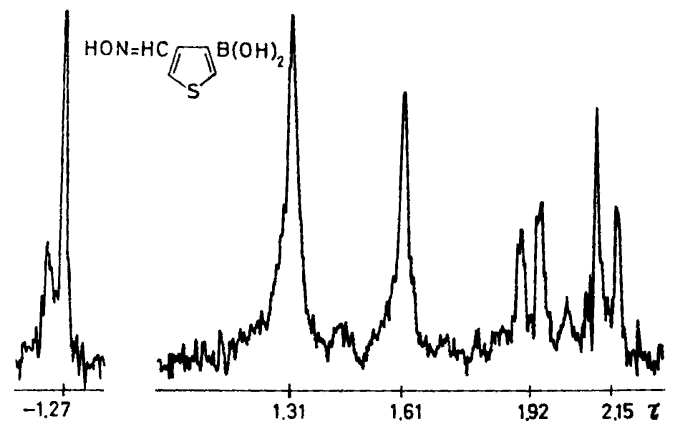

Fig. 10. NMR-spectrum at $60 \mathrm{Mc} / \mathrm{s}$ of 4-formyl-3-thiophenboronic acid oxime in DMSOsolution.

XXII shows the characteristic low-field oximic OH resonance at $-1.27 \tau$. The extra peak at $-1.32 \tau$ probably stems from deboronated product as do some other small peaks. In 2-thiophene aldoxime this resonance falls at $-1.98 \tau$ and in 3-thiophene aldoxime at $-1.88 \tau$. The boronic acid $\mathrm{OH}$ resonance of XXII falls at $1.31 \tau$, the oximic CH at $1.61 \tau$ and the two thiophenic doublets at $1.92 \tau$ and $2.15 \tau$ with a coupling constant of $3.2 \mathrm{c} / \mathrm{s}$. The low field thiophenic hydrogen shows additional splitting, due to long-range coupling to the oximic CH. Assuming the same coupling pattern as in 3-thiophene aldehydes, ${ }^{23}$ this identifies the $1.92 \tau$ band as the resonance of hydrogen 2. The oxime (XXIII) of XIV was obtained pure and showed an NMR-spectrum very similar to that of XXII. The oximic OH resonance 

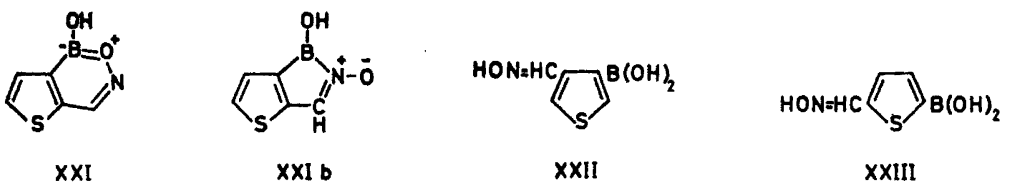

occurred at $-1.19 \tau$, the oximic $\mathrm{CH}$ at $1.61 \tau$ and the two thiophenic doublets at $2.16 \tau$ and $2.40 \tau$ with a $J_{34}$ coupling of $3.8 \mathrm{c} / \mathrm{s}$.

As mentioned earlier, long-range couplings between protons situated in different rings in XVIII, XXI, and XIX have been found. This type of longrange coupling have been observed earlier in benzofurans, ${ }^{24}$ indenes, ${ }^{24,25}$ thiophthene, ${ }^{26}$ quinolines, ${ }^{27}$ and other polynuclear compounds (for review cf. Ref. 28). In all these compounds, these couplings take place across five bonds in a particular spatial arrangement, namely forming the straightest zig-zag path. ${ }^{29}$ This would indicate that in XVIII and XXI the couplings are from hydrogen 7 to the 3 -hydrogen of the thiophene ring. This is very interesting as in the 2-thiophene aldoxime the coupling is to the 5-hydrogen. ${ }^{30}$ This difference could depend upon different conformations in the "cyclic" and "open" oxime, and not necessarily indicate different coupling mechanisms for inter-ring couplings and for the aldehydic and oximic $\mathrm{C}-\mathrm{H}$ long-range couplings.

A more detailed discussion, however, has to wait until it has been experimentally verified that the long-range coupling in XXI indeed is to hydrogen 3.

Using the above mentioned rule for identifying coupling hydrogens it seems probable that the long-range coupling is between hydrogen 4 and hydrogen 1 in XIX.

\section{UV-SPECTRA}

The similarity of the UV-spectra of derivatives of 4,3-borazaroisoquinoline to that of isoquinoline gives strong evidence for the aromatic nature of the former. ${ }^{3}$ We have therefore studied the UV-spectra of our compounds. Unfortunately, although the UV-spectrum of thieno[2,3-c]pyridine, the classical analogue of XVIII, has been obtained, only the position of the maxima and their extinction coefficient have been published, ${ }^{32}$ so a detailed comparison of the UV-spectra is not possible. However, there are some similarities. A comparison of the UV-spectra (Fig. 11) of the two open phenylhydrazones XVI and XVII and of the cyclic XV show some important differences. The former show maxima at $334 \mathrm{~m} \mu$ and $303 \mathrm{~m} \mu$, and at $370 \mathrm{~m} \mu$ and $294 \mathrm{~m} \mu$, respectively, probably characteristic of the phenylhydrazone part as for instance the phenylhydrazone of benzaldehyde has this maximum at $340 \mathrm{~m} \mu$ and $300 \mathrm{~m} \mu .^{33}$ They furthermore show absorption peaks at $246 \mathrm{~m} \mu$ and $253 \mathrm{~m} \mu$ in a region characteristic of thiophenic absorption. ${ }^{31} \mathrm{XV}$ on the other hand shows no absorption in the latter region and only one band at $306 \mathrm{~m} \mu$, which of course could belong to the binuclear system. On the other hand the oxime derivatives (Fig. 12) show rather similar maxima at 287 and $278 \mathrm{~m} \mu$. The difference in extinction coefficient might, however, indicate that these electronic transitions are of different origin.

Acta Chem. Scand. 19 (1965) No. 6 


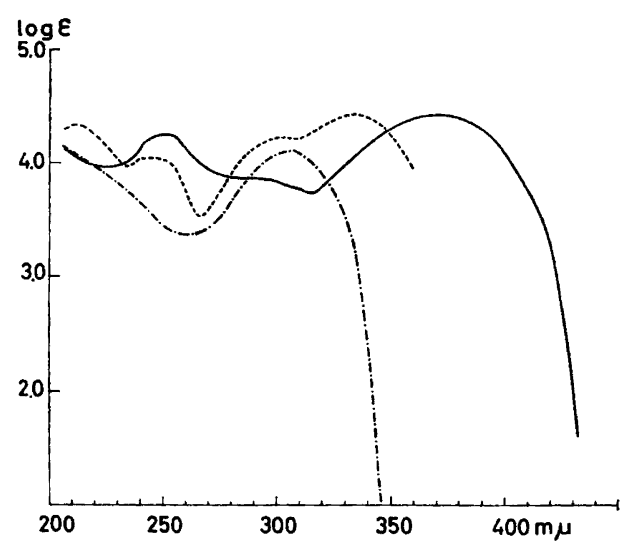

Fig. 11. UV-spectra of 4-hydroxy-5phenyl-4,5-borazarothieno[2,3-c]pyridine (-- - - ), 4-formyl-3-thiopheneboronic acid phenylhydrazone $(---)$ and 5 -formyl2-thiopheneboronic acid oxime (—).

Also XVIII and XIX show quite different UV-spectra (Fig. 13). However, with the experimental material available these differences are difficult to interpret.

It seems thus very probable that the great tendency of 2-formyl-3thiopheneboronic acid to give cyclic derivatives in contrast to 4-formyl-3thiopheneboronic acid reflect the aromatic nature of the cyclic derivatives. Preliminary investigations together with Mr. J. Namtvedt indicate that heterocyclic systems also can be obtained through the reaction of 3-formyl2-thiopheneboronic acid with hydrazine derivatives, which appear to be aromatic and show very high resistance towards acid hydrolysis. We are continuing our study of the chemical and physical properties of these new heterocyclic systems.

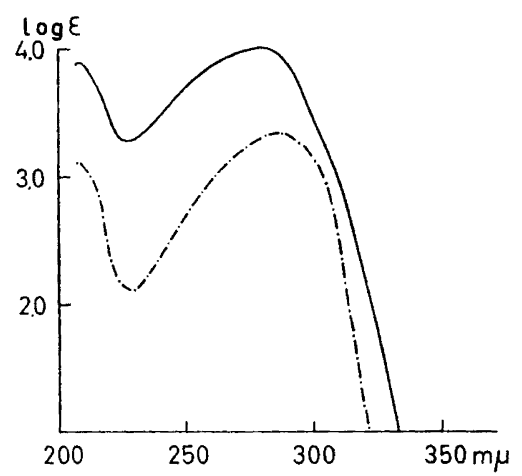

Fig. 12. UV-spectra of 4-hydroxy-4,5boroxarothieno[2,3-c]pyridine $\left(-\frac{}{-}\right)$
and 5-formyl-2-thiopheneboronic acid oxime $(-\cdots-)$.

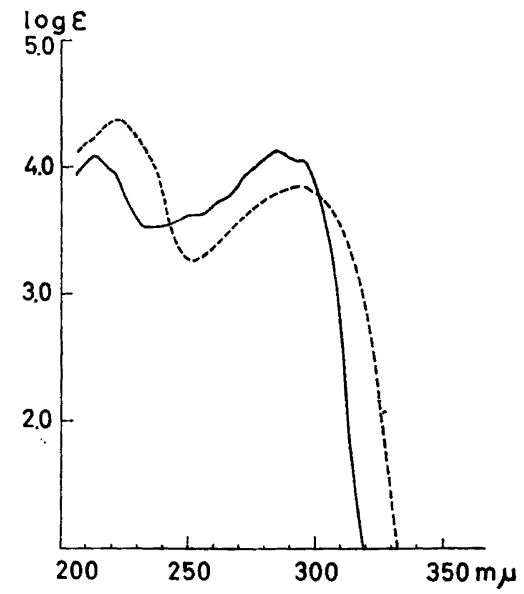

Fig. 13. UV-spectrum of 4-hydroxy-4,5borazarothieno[2,3-c]pyridine (and 7-hydroxy-7,6-borazarothieno[3,4-c]pyridine $(-\cdot-\cdot-)$.

Acta Chem. Scand. 19 (1965) No. 6 


\section{EXPERIMENTAL}

2-Formyl-3-thiopheneboronic acid. A solution of $86 \mathrm{~g}(0.37$ mole) of 2-(3-bromo-2thienyl)-1,3-dioxolane ${ }^{19}$ in $200 \mathrm{ml}$ of dry ether was added in $10 \mathrm{~min}$ to $361 \mathrm{ml}$ of a well stirred ethereal solution of $1.1 \mathrm{~N}$ butyllithium under nitrogen. After stirring for an additional $10 \mathrm{~min}, 103 \mathrm{~g}(0.45 \mathrm{~mole})$ of butyl borate in $400 \mathrm{ml}$ of dry ether was added all at once. The reaction mixture was stirred at $-70^{\circ}$ for $4 \mathrm{~h}$ and then allowed to warm to room temperature. Under ice-cooling $500 \mathrm{ml}$ of $1 \mathrm{~N}$ hydrochloric acid was added and the mixture stirred for $1 \mathrm{~h}$. The aqueous phase was extracted once with ether and the combined ether phases extracted with three $200 \mathrm{ml}$ portions of $1 \mathrm{~N}$ sodium carbonate solution. Upon acidification with $2 \mathrm{~N}$ hydrochloric acid with ice-cooling, $44.6 \mathrm{~g}$ of the boronic acid separated. Recrystallization from ethanol-water yielded $37.4 \mathrm{~g}(66 \%)$ of 2-formyl-3-thiopheneboronic acid as pale yellow prisms. The analytical sample was recrystallized once more from water. The acid decomposed on heating. The acid can be obtained in two different polymorphic forms having somewhat different IR-spectra in the solid state but identical spectra in chloroform solution. NMR (DMSO): $\tau_{\text {CHO }}-0.32$; $\tau_{5} 1.89 ; \tau_{4} 2.46 ; J_{45} 5.1 \mathrm{c} / \mathrm{s} ; J_{\text {CHO-5 }} 1.4 \mathrm{c} / \mathrm{s}$. [Found: $\mathrm{C} \mathrm{38.44;} \mathrm{H} \mathrm{3.37.} \mathrm{Calc.} \mathrm{for} \mathrm{C}_{5} \mathrm{H}_{5} \mathrm{BO}_{3} \mathrm{~S}$ (156.0): C 38.50; H 3.24].

4-Formyl-3-thiopheneboronic acid. This acid was prepared as described above from $42.7 \mathrm{~g}(0.18 \mathrm{~mole})$ of 2-(4-bromo-3-thienyl)-1,3-dioxolane, ${ }^{19} 180 \mathrm{ml}$ of $1.1 \mathrm{~N}$ butyllithium and $56.4 \mathrm{~g}(0.25$ mole) of butyl borate.

Upon hydrolysis of the reaction mixture with $1 \mathrm{~N}$ hydrochloric acid, $7.5 \mathrm{~g}$ of the boronic acid precipitated and was filtered off. From the sodium carbonate extracts an additional $11.1 \mathrm{~g}$ of boronic acid was obtained. The two acid fractions were combined and crystallized from ethanol-water, yielding $14.1 \mathrm{~g} \mathrm{(49 \% )} \mathrm{of} \mathrm{4-formyl-3-thiopheneboronic} \mathrm{acid}$ as pale brown prisms decomposing between 135 and $180^{\circ}$, which had the same IR. spectrum as the analytical sample. NMR (DMSO): $\tau_{\mathrm{CH}}-0.18 ; \tau_{5} 1.09 ; \tau_{2} \cdot 1.75 ; \tau_{\mathrm{OH}} 1.26$; $J_{25} 3.0 \mathrm{c} / \mathrm{s} ; J_{\mathrm{CHO}-2} 0.9 \mathrm{c} / \mathrm{s}$. [Found: $\mathrm{C} 38.63 ; \mathrm{H}$ 3.36. Calc. for $\mathrm{C}_{5} \mathrm{H}_{5} \mathrm{BO}_{3} \mathrm{~S}(156.0)$ : C 38.50; H 3.24].

5-Formyl-2-thiopheneboronic acid. This acid was prepared as described above from $14.5 \mathrm{~g}\left(0.062\right.$ mole) of 2-(5-bromo-2-thienyl)-1,3-dioxolane, ${ }^{19} 61 \mathrm{ml}$ of $1.1 \mathrm{~N}$ butyllithium and $19.0 \mathrm{~g}(0.083$ mole) of butyl borate. $6.0 \mathrm{~g}$ of crude acid was obtained yielding $5.5 \mathrm{~g}$ $(57 \%)$ of 5-formyl-2-thiopheneboronic acid after recrystallization, which decomposed on heating. Also after several recrystallizations, the analysis of this acid was not quite satisfactory. NMR (acetone): $\tau_{\mathrm{CH}} 0 ; \tau_{3} 2.03 ; \tau_{4} 2.22 ; J_{34} 3,8 \mathrm{c} / \mathrm{s}$. [Found: C 37.54; H 3.36. Calc. for $\mathrm{C}_{5} \mathrm{H}_{5} \mathrm{BO}_{3} \mathrm{~S}$ (156.0): $\mathrm{C} \mathrm{38.50;} \mathrm{H}$ 3.24].

4-Hydroxy-5-phenyl-4,5-borazarothieno[2,3-c]pyridine. To a hot solution of $2.0 \mathrm{~g}$ (0.013 mole) of 2-formyl-3-thiopheneboronic acid in $75 \mathrm{ml}$ of water was added drop-wise $2.0 \mathrm{~g}$ of phenylhydrazine dissolved in a little ethanol. A brownish oil separated, which on cooling solidified. The solid was dissolved in chloroform and the solution evaporated to dryness, yielding $3.0 \mathrm{~g}(94 \%)$ of yellow coloured crude product. After recrystallization from a mixture of chloroform-petrolether (b.p. $40-60^{\circ}$ ), colourless fine crystals, m.p. $147-153^{\circ}$, were obtained. NMR (DMSO): $\tau_{\mathrm{OH}} 1.05 ; \tau_{7} 1.57 ; \tau_{2,3} 2.08 ; \tau_{\mathrm{C}_{6} \mathrm{H}_{\mathrm{s}}} \approx 2.5$. UV [ethanol, $\lambda_{\max } \mathrm{m} \mu\left(\varepsilon \times 10^{-3}\right)$ ] 208, (13.7); 306 (13.2). [Found: C 57.74; H 3.70; N 12.24. Calc. for $\mathrm{C}_{11} \mathrm{H}_{9} \mathrm{BN}_{2} \mathrm{OS}$ (228.1): C 57.92; $\mathrm{H}$ 3.98; $\mathrm{N}$ 12.28]. The product which crystallized after the m.p. determination, melted at $188-190.5^{\circ}$.

4-Hydroxy-4,5-borazarothieno[2,3-c]pyridine. To a solution of $2.6 \mathrm{~g}(0.017 \mathrm{~mole})$ of 2-formyl-3-thiopheneboronic acid in $10 \mathrm{ml}$ of ethanol and $30 \mathrm{ml}$ of ether was added dropwise $2 \mathrm{ml}$ of $99 \%$ hydrazine dissolved in $10 \mathrm{ml}$ of ethanol and $2 \mathrm{ml}$ of ether. A brown-red oil separated, which crystallized during evaporation of the solvent in vacuo yielding $2.5 \mathrm{~g}(99 \%)$ of the product. Recrystallization from water did not change the IR-spectrum and yjelded slightly yellow needles melting at $127-146^{\circ}$ with decomposition. NMR (DMSO): $\tau_{\mathrm{NH}}-0.29 ; \tau_{\mathrm{OH}, \mathrm{CH}} 1.81 ; \tau_{2,3} 2.21,2.28 ; J_{23} 5.3 \mathrm{c} / \mathrm{s}$. UV [ethanol, $\lambda_{\max } \mathrm{m} \mu$ $\left.\left.\left(\varepsilon \times 10^{-3}\right)\right] 213,(12.2) 221 \mathrm{sh},(9.05), 262\right] \mathrm{sh}(5.34), 274$ sh (9.36), $285(13.7), 293(11.3)$. [Found: C 39.32; $\mathrm{H} \mathrm{3.52;} \mathrm{N}$ 18.55. Calc. for $\mathrm{C}_{5} \mathrm{H}_{5} \mathrm{BN}_{2} \mathrm{OS}$ (152.0): C 39.51; $\mathrm{H} \mathrm{3.32;} \mathrm{N} 18.43$ ]. The product which crystallized after the m.p. determination, melted at $160-161^{\circ}$.

4-Hydroxy-4,5-boroxarothieno[2,3-c]pyridine. To a hot solution of $2.5 \mathrm{~g}(0.016 \mathrm{~mole})$ of 2-formyl-3-thiopheneboronic acid in $100 \mathrm{ml}$ of water was added $1.8 \mathrm{~g}$ of hydroxylamine hydrochloride dissolved in $5 \mathrm{ml}$ of water. After cooling the $\mathrm{pH}$ was adjusted to 6 with $2 \mathrm{~N}$ sodium hydroxide, and on standing, $0.75 \mathrm{~g}(31 \%)$ of colourless needles of 4-hydroxy-

Acta Chem. Scand. 19 (1965) No. 6 
4,5-boroxarothieno[2,3-c]pyridine crystallized. Recrystallization from water did not change its IR-spectrum, and the compound melted with decomposition at $144^{\circ}-146.5^{\circ}$. NMR (DMSO): $\tau_{\mathrm{OH}} 0.46 ; \tau_{7} 1.08 ; \tau_{2,3} 1.95 ; 2.30 ; J_{45} 5.0 \mathrm{c} / \mathrm{s}$. UV [ethanol, $\left.\lambda_{\max } \mathrm{m} \mu\left(\varepsilon \times 10^{-3}\right)\right]$ : 209 (8.05); 278 (10.2). [Found: C 39.22; H 2.46; $\mathrm{N} \mathrm{9.39}$. Calc. for $\mathrm{C}_{5} \mathrm{H}_{4} \mathrm{BNO}_{2} \mathrm{~S}(153.0)$ :

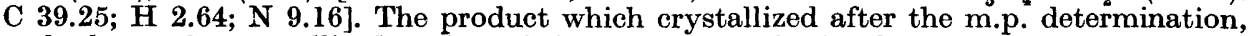
melted at $182^{\circ}$, crystallized again and decomposed on further heating.

4-Formyl-3-thiopheneboronic acid phenylhydrazone. To a hot solution of $1.5 \mathrm{~g}(0.0096$ mole) of 4-formyl-3-thiopheneboronic acid in $75 \mathrm{ml}$ of water and $25 \mathrm{ml}$ of ethanol was added drop-wise with vigorous stirring $1.5 \mathrm{~g}$ of phenylhydrazine dissolved in a little ethanol-water. $2.0 \mathrm{~g}(85 \%)$ of a crystalline product separated which was recrystallized from toluene and decomposed on heating. NMR (DMSO): $\tau_{\mathrm{NH}}-0.25 ; \tau_{\mathrm{OH}} 1.05 ; \tau_{\mathrm{CH}} 1.75$ $\tau_{2,5} 1.96,2.21 ; \tau_{\mathrm{C}_{6} \mathrm{H}_{5}} \approx 2.9 . J_{25} 3.0 \mathrm{c} / \mathrm{s}$. UV [ethanol, $\lambda_{\max } \operatorname{m} \mu\left(\varepsilon \times 10^{-3}\right)$ ]: $212(21.8), 246$ (11.3), 303 (16.7), 334 (26.4). [Found: C 53.81; $\mathrm{H} 4.57 ; \mathrm{N}$ 11.67. Calc. for $\mathrm{C}_{11} \mathrm{H}_{11} \mathrm{BN}_{2} \mathrm{O}_{2} \mathrm{~S}$ (246.1): C 53.68; H 4.51; N 11.38].

4-Formyl-3-thiopheneboronic acid oxime. $2.0 \mathrm{~g}(0.013 \mathrm{~mole})$ of 4-formyl-3-thiopheneboronic acid and $1.64 \mathrm{~g}$ of hydroxylamine hydrochloride were dissolved in $100 \mathrm{ml}$ of hot water. The mixture was allowed to stand over-night, and the $\mathrm{pH}$ adjusted to 3 with $1 \mathrm{~N}$ sodium hydroxide and the precipitate $(2.0 \mathrm{~g} 91 \%)$ filtered off. Even after two recrystallizations from methanol, the oxime was still impure. The product decomposed at about $180^{\circ}$. NMR (DMSO): $\tau_{\mathrm{OH}}-1.27 ; \tau_{\mathrm{B}(\mathrm{OH})} 1.31 ; \tau_{\mathrm{CH}} 1.61 ; \tau_{2} 1.92 ; \tau_{5} 2.15 ; J_{25} 3.2 \mathrm{c} / \mathrm{s}$. [Found: $\mathrm{C} 39.01 ; \mathrm{H} 4.09 ; \mathrm{N} 7.99$. Calc. for $\mathrm{C}_{5} \mathrm{H}_{6} \mathrm{BNO}_{3} \mathrm{~S}(171.0): \mathrm{C} 35.12 ; \mathrm{H} \mathrm{3.54;} \mathrm{N} 8.19$ ]. 7-Hydroxy-7,6-borazarothieno[3,4-c]pyridine. $1.3 \mathrm{~g}(0.0085$ mole $)$ of 4-formyl-3thiopheneboronic acid was treated with $1 \mathrm{ml}$ of $99 \%$ hydrazine as described above for 2-formyl-3-thiopheneboronic acid, yielding $1.2 \mathrm{~g}(93 \%)$ of crude product, which was recrystallized from ethanol-water, m.p. with decomposition $150-164^{\circ}$. NMR (DMSO): $\tau_{\mathrm{NH}} 0.65 ; \tau_{\mathrm{OH}} 1.61 ; \tau_{1} 1.73 ; \tau_{3} 2.00 ; \tau_{4} 2.09 ; J_{13} 2.6 \mathrm{c} / \mathrm{s} ; J_{14} 0.7 \mathrm{c} / \mathrm{s}$. UV [ethanol, $\lambda_{\max } \mathrm{m} \mu$ $\left(\varepsilon \times 10^{-3}\right): 222(23.6), 295(7.16)$. [Found: $\mathrm{C} \mathrm{39.45;} \mathrm{H} \mathrm{3.33} ; \mathrm{N}$ 18.80. Calc. for $\mathrm{C}_{5} \mathrm{H}_{5} \mathrm{BN}_{2} \mathrm{OS}$ (152.0): C 39.51; H 3.32; N 18.43].

5-Formyl-2-thiopheneboronic acid phenylhydrazone. To a solution of $1.5 \mathrm{~g}(0.0096$ mole) of 5-formyl-2-thiopheneboronic acid in $25 \mathrm{ml}$ of water was added, drop-wise with stirring, $1.5 \mathrm{~g}$ of phenylhydrazine dissolved in water-ethanol. $2.0 \mathrm{~g}(85 \%)$ of the phenylhydrazone separated and was recrystallized from ethanol-water, m.p. $130-140^{\circ}$ (decomp.). NMR (DMSO): $\tau_{\mathrm{NH}}-0.24 ; \tau_{\mathrm{OH}} 1.81 ; \tau_{\mathrm{CH}} 1.91 ; \tau_{3,4} 2.38,2.81 ; \tau_{\mathrm{C}_{6} \mathrm{H}_{5}} \approx 3 ; J_{34} 3.4 \mathrm{c} / \mathrm{s}$. UV [ethanol, $\lambda_{\max } \operatorname{m} \mu\left(\varepsilon \times 10^{-3}\right)$ ]: 253 (18.1), 294 (7.32), 370 (27.3). [Found: C 54.40; H 4.17; $\mathrm{N}$ 11.45. Calc. for $\mathrm{C}_{11} \mathrm{H}_{11} \mathrm{BN}_{2} \mathrm{O}_{2} \mathrm{~S}(246.1)$ : $\mathrm{C} 53.68 ; \mathrm{H} 4.51 ; \mathrm{N} 11.38$ ]. Attempts to recrystallize from acetic acid led to deboronation yielding the phenylhydrazone of 2-thiophene aldehyde, m.p. $134-138^{\circ}$ (Lit. value ${ }^{34} 134-135^{\circ}$. [Found: C 65.24; H 4.86;N14.06. Calc. for $\mathrm{C}_{11} \mathrm{H}_{10} \mathrm{~N}_{2} \mathrm{~S}(202.3)$ : $\left.\mathrm{C} 65.30 ; \mathrm{H} 4.98 ; \mathrm{N} 13.86\right]$.

5 -Formyl-2-thiopheneboronic acid oxime. $1.0 \mathrm{~g}(0.0066 \mathrm{~mole})$ of 5 -formyl-2-thiopheneboronic acid and $0.82 \mathrm{~g}$ of hydroxylamine hydrochloride were dissolved in $50 \mathrm{ml}$ of water. On cooling $0.9 \mathrm{~g}(82 \%)$ of the oxime separated in needles, which were recrystallized from water. The oxime decomposed on heating. NMR (DMSO): $\tau_{\mathrm{OH}}-1.19 ; \tau_{\mathrm{CH}} 1.61 ; \tau_{3,4} 2.16$, $2.40 ; J_{34} 3.8 \mathrm{c} / \mathrm{s}$. UV [ethanol, $\lambda_{\max } \mathrm{m} \mu\left(\varepsilon \times 10^{-3}\right)$ ]: 208 (1.34), 287 (2.26). [Found: C 35.43; $\mathrm{H} 3.53 ; \mathrm{N}$ 8.24. Calc. for $\mathrm{C}_{5} \mathrm{H}_{6} \mathrm{BNO}_{3} \mathrm{~S}(171.0)$ : $\mathrm{C} 35.12 ; \mathrm{H} 3.54 ; \mathrm{N} 8.19$ ].

5-Formyl-2-thiopheneboronic acid azine. $1.3 \mathrm{~g}(0.0083 \mathrm{~mole})$ of 5 -formyl-2-thiopheneboronic acid was treated with $1 \mathrm{ml}$ of $99 \%$ hydrazine in the same way as 2-formyl-3thiopheneboronic acid, yielding $1.4 \mathrm{~g}$ of an oily product. This was dissolved in water and the $\mathrm{pH}$ adjusted to 6 with $2 \mathrm{~N}$ hydrochloric acid, which caused the separation of $1.2 \mathrm{~g}(93 \%)$ of a yellow crystalline product, the IR-spectrum of which did not change upon recrystallization from aqueous ethanol. The compound decomposed on heating and elementary analyses indicated it to be a somewhat impure azine of 5-formyl-2. thiopheneboronic acid. [Found: $\mathrm{C} 39.89 ; \mathrm{H} 3.85 ; \mathrm{N} 9.15$. Calc. for $\mathrm{C}_{10} \mathrm{H}_{10} \mathrm{~B}_{2} \mathrm{~N}_{2} \mathrm{O}_{4} \mathrm{~S}_{2}$ (308.0): C 39.00; H 3.27; N 9.107.

The mass spectra were, through the courtesy of Perkin-Elmer, obtained by Dr. J. Seibl on a Hitachi Perkin-Elmer RMU-6A Mass spectrometer equipped with a Micro-Tek inlet system heated to a temperature of $80^{\circ}$, with an electron multiplier functioning as a collector.

The NMR-spectra were obtained on a Varian Associates DP-60 model V-4302 NMRspectrometer operating at $60 \mathrm{Mc} / \mathrm{s}$ and a 12" Varian magnet V.4012 A, equipped with integrator and back-ground stabilizer. The magnet sweep was calibrated using the 
modulation side-band technique. The variable frequency was obtained from a Hewlett Packard Wide range oscillator model $200 \mathrm{CD}$ and measured with a Beckman, Model 6146 Universal EPUT timer. The IR-spectra were recorded on a Beckman IR-5A infrared spectrophotometer. The UV-spectra were recorded on a Beckman DK-1 UV-spectrophotometer.

Acknowledgements. The authors are indebted to fil.lic. Anna-Britta Hörnfeldt and Miss Merete Lange for the NMR-spectra, and to Dr. J. Seibl, ETH, Zürich, for the mass spectra. The elementary analyses were carried out by Ilse Beetz, Mikroanalytisches Laboratorium, Kronach.

\section{REFERENCES}

1. Dewar, M. J. S. and Poesche, W. H. J. Org. Chem. 29 (1964) 1757.

2. Dewar, M. J. S. In Steinberg, H. and McCloskey, A. L. Eds. Progress in Boron Chemistry, Pergamon Press 1964, Vol. 1, p. 235.

3. Dewar, M. J. S. and Dougherty, R. C. J. Am. Chem. Soc. 86 (1964) 433.

4. Dewar, M. J. S. and Kubba, V. P. Tetrahedron 7 (1959) 213.

5. Dewar, M. J. S. and Kubba, V. P. J. Org. Chem. 25 (1960) 1722.

6. Dewar, M. J. S. and Kubba, V. P. J. Am. Chem. Soc. 83 (1961) 1757.

7. Dewar, M. J. S. and Dietz, R. J. Org. Chem. 26 (1961) 3253.

8. Dewar, M. J. S., Kubba, V. P. and Pettit, R. J. Chem. Soc. 19583076.

9. Dewar, M. J. S. and Dietz, R. J. Chem. Soc. 19592728.

10. Lennarz, W. J. and Snyder, H. R. J. Am. Chem. Soc. 82 (1960) 2172.

11. Dewar, M. J. S. and Dietz, R. Tetrahedron 15 (1961) 26.

12. Edvards, J. O., Morrison, G. C., Ross, V. F. and Schultz, J. W. J. Am. Chem. Soc. 77 (1955) 266.

13. McDaniel, D. H. and Brown, H. C. J. Am. Chem. Soc. 77 (1955) 3756.

14. Dewar, M. J. S. and Maitlis, P. M. Tetrahedron 15 (1961) 35.

15. Dewar, M. J. S. and Maitlis, P. M. J. Am. Chem. Soc. 83 (1961) 187.

16. Mayer, R., Kleinert, H., Richter, S. and Gewald, K. Angew. Chem. 74 (1962) 118.

17. Dann, O. and Dimmling, W. Chem. Ber. 87 (1954) 373.

18. Bak, B., Christensen, P., Hansen Nygaard, L. and Rastrup-Andersen, J. J. Mol. Spectry. 7 (1961) 58.

19. Gronowitz, S., Biezais, A. and Mathiasson, B. Arkiv Kemi 21 (1963) 265.

20. Snyder, H. R., Konecky, M. S. and Lennarz, W. J. J. Am. Chem. Soc. 80 (1958) 3611.

21. Skowronska-Serafinowa, B. and Makosza, M. Roczniki Chem. 35 (1961) 937.

22. Santucci, L. and Gilman, H. J. Am. Chem. Soc. 80 (1958) 193.

23. Hoffman, R. A. and Gronowitz, S. Arkiv Kemi 16 (1960) 563.

24. Elvidge, J. A. and Foster, R. G. J. Chem. Soc. 1963590.

25. Elleman, D. O. and Manatt, S. I. J. Chem. Phys. 36 (1962) 2346.

26. Gestblom, B. Acta Chem. Scand. 17 (1963) 280.

27. Anet, F. A. L. J. Chem. Phys. 32 (1960) 1274.

28. Sternhell, S. Rev. Pure Appl. Chem. 14 (1964) 15.

29. Banwell, C. N. and Sheppard, N. Discussions Faraday Soc. 34 (1962) 115.

30. Gronowitz, S. and Hoffman, R. A. Acta Chem. Scand. 13 (1959) 1687.

31. Gronowitz, S. Arkiv Kemi 13 (1958) 239.

32. Herz, W. J. Am. Chem. Soc. 75 (1953) 5122.

33. Ramart-Lucas, M., Hoch, J. and Martynoff, M. Bull. Soc. Chim. France 1937481.

34. Hantsch, A. Ber. 22 (1889) 2827.

Received March 16, 1965. 